\title{
Der Verdacht de Friedrich Dürrenmatt: Propuesta didáctica y actos de habla en lengua alemana
}

\author{
VICTORIIG GasPaR VERDÚ \\ Universidad Jaume I Castellón
}

Desde siempre Friedrich Dürrenmatt ha sido uno de mis autores preferidos en lengua alemana, junto con M. Walser, S. Zweig y B.Brecht. Admiro en todos ellos su escritura elegante y grácil, su capacidad crítica, su fina ironía. Sin embargo de Dürrenmatt me llama especialmente su pluma, tan afilada y directa como la punta del bisturí de un cirujano. Me sorprende de él y de sus novelas policíacas ese modo de escribir tan limpio, tan rápido, ese acercamiento a la escena del crimen diseccionando con minuciosidad y calma la mente del asesino, de sus cómplices y de su implacable perseguidor, en la obra que nos ocupa, el comisario Bärlach.

Es un hecho conocido que Dürrenmatt se inició y continuó en la novela policíaca por problemas económicos. Así lo reconocía él mismo en una entrevista:

Ich hatte plötzlich nichts mehr. Da musste ich schreiben, ich hatte keine andere Wahl. Also schrieb ich auf einen Auftrag hin die Kriminalromane «Der Richter und sein Henker» und «Der Verdacht».Für den ersten bekam ich, glaube ich, 1000 und für den zweiten 2000 Franken. LächerlicheSummen. Der Verdacht wurde übrigens gleichzeitig geschrieben und gedrückt, das heisst, alle vierzehn Tage musste ich ein Fortsetzungs-Manuskript abliefern, das dann sofort gedrückt wurde. (Dürrenmatt in Fringeli: 7).

Las obligadas entregas semanales de Der Richter und sein Henker para el diario Der Schweizerische Beobachter salvaron al matrimonio Dürrenmatt de fuertes apuros económicos. No obstante, y a pesar de la obligación de escribir y publicar en el diario suizo, esto no le impidió convertirse en un gran maestro del género policíaco. Parece que fue el aumento de sueldo el motivo que le impulsó a revivir al comisario Bärlach en su segunda novela policíaca Der Verdacht, por la que cobró justo el doble que por la primera, Der Richter und Sein Henker.

Der Verdacht conecta directamente con lo sucedido al final de Der Richter und sein Henker, es su continuación directai. El comisario Bärlach, tras descubrir al asesino del anterior caso, es ingresado en una clínica para ser sometido a una operación. Aquí se inicia Der Verdacht. Durante su convalecencia en la clínica, le pasa visita su amigo y médico el doctor Hungertobel. El comisario yace enfermo en cama y observa palidecer el rostro de su amigo, que ha venido a visitarlo y está ojeando un número de la revista Life. Una foto llama poderosamente la atención del doctor, quien cree reconocer en ella a un antiguo médico de las SS, llamado Dr. Nehle y acusado de operar pacientes sin anestesia por puro sadismo. No obstante intenta olvidar la idea, pero el comisario insiste (1985: 126):

Willst du mir nicht sagen, warum du bleich geworden bist wie ein Toter, als ich dir dieses Bild im 'Life' zeigte?, fragte der Kranke(...) 'Es war ein lächerlicher Irrtum, Hans', sagte er, 'Nicht der Rede wert'.

'Dukennst diesen Dr.Nehle?' Bärlachs Stimmeklang seltsamerregt. 'Nein' antwortete Hungertobel, 'ich kenne ihn nicht',. 'Er hat mich nur an jemanden erinnert'.

Es el doctor quien infunde la sospecha en el comisario Bärlach de que el supuesto Dr Emmenberger, en la actualidad director de una conocida clínica en Zurich, y cuya foto tiene delante de sus ojos, guarda un increíble parecido con Dr. Nehle. El comisario decide investigar el tema aunque sabe que sus días están contados y sus fuerzas muy mermadas (1985: 130):

'Der Verdacht', sagte der Alte in seinem Bett, und dann noch einmal unerbittlich: 'Der Verdacht'.

Hungertobel blieb an Bärlachs Bett stehen: 'Vergessen wir dieses Gespräch, Hans', sagte er. 'Wir liessen uns gehen'. Freilich, man liebt es manchmal, mit Möglichkeiten zu spielen. Das tut nie gut. Kümmern wir uns nicht mehr um ihn. Je mehr ich das 
policíacas que parten de un essulema lógico

y ordenado. De hecho la pura casulalidad

es la que da lugara al inicio de la investigación.
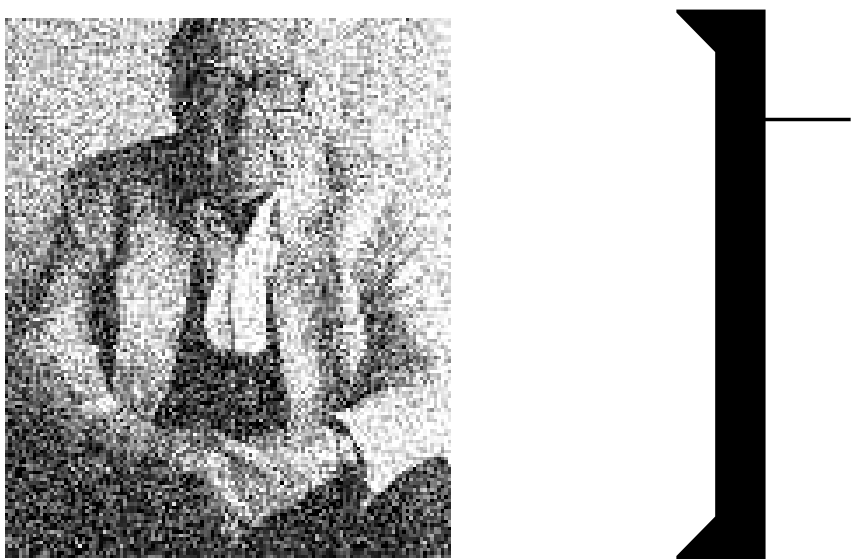

Bild ansehe, desto weniger ist er es. Das ist keine Ausrede. Er war in Chile und nicht in Stutthof, und damit ist unser Verdacht sinnlos geworden.

'In Chile, in Chile', sagte Bärlach, uns seine Augen funkelten gierig nach einem neuen Abenteuer. Sein Leib dehnte sich, und dann lag er wider unbeweglich und entspannt, die Hände hinter dem Kopf.

Der Verdacht, 1951, presenta muy poco en común con la estructura de las tradicionales novelas policíacas que parten de un esquema lógico y ordenado. De hecho la pura casualidad es la que da lugar al inicio de la investigación. Dürrenmatt no pretende descubrir al asesino, lo muestra ya al principio de la obra. Su autor acompaña al lector a descubrir paso a paso los motivos que han movido al asesino y a sus cómplices a esconder su identidad y seguir delinquiendo. Al igual que en su anterior novela, el comisario Bärlach no emplea conocimientos modernos de criminología, sino que inicia el seguimiento más tradicional. Se hace ingresar en la clínica de Zürich, donde trabaja el supuesto criminal de guerra Dr.Emmenberger y en este escenario Dürrenmatt construye con gran maestría una atmósfera en la que aparecen los más variopintos personajes y una acción cargada de intriga. Elementos como el primer interrogatorio, la comprobación de que Nehle y Emmenberger son el mismo, el sadismo de Emmenberger, la aparición de personajes variopintos como el judío gigante, el enano, la amante, todo ello nos sumerge en un ritmo trepidante en la novela que se mantiene hasta el último momento.

El desenlace de Der Verdacht, con el triunfo del comisario Bärlach y la derrota del sádico Emmenberger, transmite cierto optimismo al lector. Esta historia cargada de intriga hubiera sido más dura si el malvado Emmenberger hubiera salido impune sin ser descubierto y castigado, tal y como sucedió en la realidad con muchos criminales de guerra nazis.

\section{PROPUESTA DIDÁCTICA I: BUSQUEDA DE CONEXIÓN CON LA REALIDAD HISTÓRICA}

Nivel: Mittelstufe 3/Oberstufe

Tiempo: 2 sesiones 50 minutos

Forma social: parejas o grupos de tres personas

Proponemos a los alumnos que hagan una búsqueda por Internet propia de detectives. Con ayuda de las siguientes direcciones, les instamos a que busquen una segunda lectura de esta obra, además de la policíaca, dado que Der Verdacht tiene una cone- xión documental con la realidad, y denuncia un tema histórico ${ }^{2}$. http://www.lesekost.de/deutsch/ch/HHLDCH03.htm

http://www.buecher4um.de/Rezensionen/Besprechungen/TUV/ Verdacht.htm

http://www.alex-hartmann.net/duerrenmatt/suspect1.html

1. ¿Qué conocido doctor nazi de las SS operaba sin anestesia, y hacía sádicos experimentos con niños y gemelos?

2. ¿En qué conocida universidad alemana estudió? ¿Cuál fue el título de sus tesis doctoral?.

3. ¿En qué campo de concentración realizó sus sádicos experimentos y a dónde huyó tras el final de la $2^{\text {a }}$ Guerra mundial?

4. Enumera al menos cinco similitudes que aparecen en la obra entre Nehle y un conocido doctor nazi.

(Apellidos muy parecidos- nótese la presencia de la 'e' en ambos apellidos, exilio o huida a Sudamérica en el personaje real, Mengele, a Brasil, y en el ficticio, Neble, a Chile. Ambos muestran interés por mellizos y enanos, ambos son propietarios de una clínica, ambos realizan experimentos sádicos y de ningún beneficio para los pacientes)

5. ¿Año de publicación de Der Verdacht? (1951). ¿De qué eran acusados los escritores suizos en aquella época?

6. ¿Cuál consideras que fue la intención de Dürrenmatt con esta obra y este personaje? ¿Subyace una denuncia ante la sociedad?

7. En caso que sí, ¿cual? y ¿porqué no se atrevió a una denuncia clara y directa?

8. ¿Año de la muerte de Mengele? (79) ¿Lugar de la muerte de Mengele? Brasil, Sudamérica ¿Fue procesado en Nürnberg como criminal de guerra?. No.

\section{PROPUESTA DIDÁCTICA II: ACERCAMIENTO A LA OBRA LITERARIA}

Nivel: Mittelstufe 3/Oberstufe

Tiempo: 1 sesión 50 minutos

Forma social: parejas o grupos de tres personas

Planteamos la realización de un debate oral en clase, siguiendo y contestando los puntos del siguiente cuestionario. Éstos serán previamente trabajados en pequeños grupos y después en pleno con ayuda de material adicional y TIC.

1. Personenkonstellation. Plásmala en diagrama de flechas marcando la relación entre los personajes principales.

2. Autor. Ubicación de Dürrenmatt en su época y corriente literaria. Añadir otros autores contemporáneos suyos. ¿Qué tienen en común con Dürrenmatt? 
3. Descripción física e introspección psicológica de los personajes principales.

4. Momento desencadenante de la trama. Identificarlo. ¿Sucede al principio de la obra, al medio, al final?

5. ¿Qué es lo que más te ha gustado y porqué? ¿Qué es lo que menos te ha gustado y porqué?

\section{PROPUESTA DIDÁCTICA III: ACTOS DE HABLA EN LENGUA ALEMANA}

Nivel: Mittelstufe 3/Oberstufe

Tiempo: 1 sesión 50 minutos

Forma social: pequeños grupos

Al igual que muchas novelas, Der Verdacht se presta a ser dramatizado. Proponemos a los alumnos que realicen una reescritura del texto y un guión teatral. Para esto se centrarán en una escena que consideren importante y que ellos mismos acotarán. Nuestra última propuesta didáctica pasa por la reescritura y por el teatro leído, que puede ser posteriormente grabado en vídeo. Con ello añadimos la elaboración y escritura de actos de habla que impliquen expresión de irrealidad, deseo, y petición cortés.

Introducir en esta reescritura el Konjunktiv II para expresar en boca de Bärlach,

1. Irrealität

Ich würde schwören, dass er es ist.

2. Irreale Wunschsätze

2.1. kann mit wenn eingeleitet werden, oder direkt mit dem Verb in K.II

2.2 muss mit bloss, doch, nur, doch nur ergänzt werden

z. B: Wäre ich doch gesund!

2.3 am Ende steht ein Ausrufezeichen (!)

3. Höfliche Bitte.

3.1 mit Modalverben in K.II.

z. B: Könnten Sie mir sagen...?

3.2 mit K.II

z. B: Würden Sie mir bitte die Adresse geben?

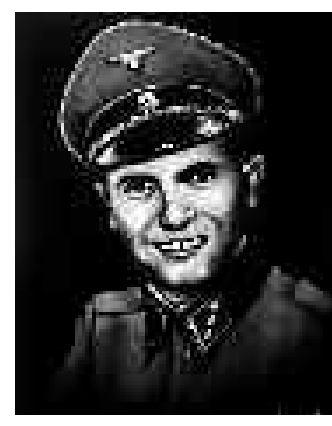

Este artículo ha supuesto para su autora navegar en la búsqueda de las similitudes entre dos personajes perversos, uno ficticio llamado Nehle y otro real llamado Mengele, para concluir que Dürrenmatt nos estaba transmitiendo una denuncia, una segunda lectura. Pensemos que hasta muy poco antes de la evacuación de Auschwitz, Mengele actuaba a sus anchas en este campo de concentración. Tras ser evacuado, regresó impune a Günzburg, en Bayern, sin ser molestado por la justicia, y allí siguió trabajando durante la época de la reconstrucción de Alemania en la fábrica de maquinaria agrícola Carl Mengele und Söhne, que daba trabajo a todo el pueblo. Nunca fue molestado.

A principios de la segunda guerra mundial, Mengele se inscribió voluntariamente en el Institut für Erbbiologie und Rassenhygiene y estuvo como soldado médico en Francia y en la Unión Soviética, donde obtuvo reconocimientos por su trabajo. En 1943 regresó voluntariamente a Auschwitz, donde con dinero público realizó investigaciones médicas de gran sadismo con seres humanos vivos y con poco o ningún beneficio para la ciencia.

El interés de Mengele se centraba en parejas de gemelos idénticos y su resistencia ante la muerte, además de los enanos como ejemplares anormales de la raza.

No sólo Dürrenmatt, también el escritor Ernst Schnabel a mitad de los años cincuenta denunció en sus publicaciones sobre Anne Frank, la situación impune en que había quedado el doctor muerte, pero éste ya había emigrado a Sudamérica. Recordemos que Dürrenmatt se adelanta a la denuncia de Schnabel, la hace con Der Verdacht en 1951. Hasta finales de los años 70 Mengele pudo huir de todos los intentos de extradición y murió en 1979 en Brasil en un dudoso accidente ${ }^{3}$. En mi opinión Der Verdacht constituye una clara acusación que invitaba en su tiempo al inicio de una investigación seria y rigurosa contra criminales de guerra que habían quedado impunes.

\section{Bibliografía relevante}

Brecht.B., (1969), Über die Popularität des Kriminalromans, in idem, Gesammelte Werke, Bd 19. (Schriften zur Literatur und Kunst 2). Frankfurt a.M., Suhrkamp,. S 450-457.

Bloch, E. (1965), Philosophische Ansicht des Detektivromans in idem, Literarische Aufsätze, Gesamtausgabe, Bd.9, Frankfurt a.M., Suhrkamp, S.247-254 f.

Chandler, R. (1944), Mord ist eine Kunst (The Simple Art of Murder), in idem (1969), Spanisches Blut. Kriminalstories. Frankfurt a.M.. Ullstein. S.154-173.

Dürrenmatt, F. (1985), Werkausgabe in
dreiBig Bänden, Bd.19, Der Richter und sein Henker, Der Verdacht, Zürich, Diogenes.

Finck, E. (2002), Theorie des Kriminalromans, Stuttgart, Reclam.

Fringeli, D., ( ). F. Dürrenmatt, in: Nachdenkenmit und über Friedrich Dürrenmatt,a.a.O.,S.7.

Grosse, W., (1998), Literaturwissen, Friedrich Dürrenmatt, Stuttgart, Reclam.

Marsch, E. (1972), Die Kriminalerzählung. Theorie, Geschichte, Analyse. München,

Pasche, W. (2005), Interpretationshilfen Friedrich Dürrenmatts Kriminalromane, Stuttgart, Klett.

Winkler, (Winckler Germanistik, Modelle und Methoden).

http://www.lesekost.de/deutsch/ch/HHLDCH03.htm
http://www.buecher4um.de/Rezensionen/Besprechungen/TUV/Verdacht.htm

http://www.alex-hartmann.net/duerrenmatt/suspect1.html

\section{Notas}

1. De hecho aparecen publicadas juntas y en ese orden en la editorial Diogenes.

2. (Dürrenmatt apunta sobradas similitudes entre Dr.Nehle y Dr. Mengele, el famoso doctor de las SS apodado «doctor muerte»).

3. No hay constancia de acta de defunción ni se sabe el lugar donde está enterrado. 